\title{
Pain in Platin-Induced Neuropathies: A Systematic Review and Meta-Analysis
}

\author{
Vasiliki Brozou · Athina Vadalouca · Panagiotis Zis $\mathbb{D}$
}

Received: September 25, 2017 / Published online: December 1, 2017

(c) The Author(s) 2017. This article is an open access publication

\begin{abstract}
Introduction: Platin-induced peripheral neuropathy (PIPN) is a common cause of PN in cancer patients. The aim of this paper is to systematically review the current literature regarding PIPN, with a particular focus on epidemiological and clinical characteristics of painful PIPN, and to discuss relevant management strategies.

Methods: A systematic computer-based literature search was conducted on the PubMed database.

Results: This search strategy resulted in the identification of 353 articles. After the eligibility assessment, 282 articles were excluded. An additional 24 papers were identified by scanning the reference lists. In total, 95 papers met the inclusion criteria and were used for this review. The prevalence of neuropathic symptoms due to acute
\end{abstract}

Enhanced content To view enhanced content for this article go to http://www.medengine.com/Redeem/ 0AECF0606291D6F7.

V. Brozou

251 Aviation General Hospital, Athens, Greece

A. Vadalouca

Athens Medical Center, Athens, Greece

P. Zis $(\square)$

Academic Department of Neurosciences, Sheffield

Teaching Hospitals NHS Foundation Trust,

Sheffield, UK

e-mail: takiszis@gmail.com toxicity of oxaliplatin was estimated at $84.6 \%$, whereas PN established after chemotherapy with platins was estimated at $74.9 \%$. Specifically regarding pain, the reported prevalence of pain due to acute toxicity of oxaliplatin was estimated at $55.6 \%$, whereas the reported prevalence of chronic peripheral neuropathic pain in PIPN was estimated at $49.2 \%$.

Conclusion: Peripheral neuropathy is a common complication in patients receiving platins and can be particularly painful. There is significant heterogeneity among studies regarding the method for diagnosing peripheral neuropathy. Nerve conduction studies are the gold standard and should be performed in patients receiving platins and complaining of neuropathic symptoms post-treatment.

Keywords: Cancer; Chemotherapy; Pain; Platin; Polyneuropathy

\section{INTRODUCTION}

The term "peripheral neuropathy" (PN) refers to various disorders of the peripheral nervous system, including single and multiple (asymmetric) mononeuropathies, symmetrical involvement of many nerves (polyneuropathy), or the sole involvement of the dorsal root ganglia $[1,2]$.

PN is very prevalent in cancer patients [3] and can be a direct or an indirect complication 
of cancer or cancer-related treatment, a pre-existing comorbidity not related to cancer, or part of a paraneoplastic syndrome [4-7].

The vast majority of chemotherapy-induced PN (CIPN) is caused by neurotoxic chemotherapy schemes, with platins (cisplatin, oxaliplatin, carboplatin) constituting the leading source of treatment-induced $\mathrm{PN}$ in cancer. Contrary to the perception that painful neuropathies are largely caused by diabetes, other forms of PN can be particularly painful, leading to poor quality of life [2]. Therefore, platin-induced peripheral neuropathy (PIPN) should be considered a major cause of pain in cancer patients [8].

The aim of this paper is to systematically review the epidemiological and clinical characteristics of painful PIPN and provide an overview of relevant management strategies.

\section{METHODS}

\section{Literature Search Strategy}

A systematic computer-based literature search was conducted August 15, 2017, on the PubMed database. For the search, we used three Medical Subject Headings (MeSH) terms in either the title or abstract, as follows: (1) "neuronopathy" or "ganglionopathy" or "neuropathy" or "polyneuropathy"; (2) "pain" or "painful"; (3) "chemotherapy" or "platin" or "platins" or "oxaliplatin" or "cisplatin". Articles were limited to English language, species to human, and with full text available. We also perused the reference lists of the papers in order to identify papers not found through the search strategy.

\section{Inclusion and Exclusion Criteria}

Articles eligible for inclusion in the review were required to meet the following criteria:

1. Involved case series with platin-induced PN.

2. Studied human adult subjects.

The following were excluded:

1. Book chapters, reviews, letters to the editor, and editorials that did not provide new data.
2. Papers providing incomplete clinical or neurophysiological data about the single cases/case series.

\section{Data Extraction}

Data were extracted from each study in a structured coding scheme using Microsoft Excel, and included information on the article identification, year of publication, evaluation period, total number of subjects, gender, age, presence of pain in general, presence of pain secondary to the neuropathy, neurophysiological type of neuropathy, course of symptoms, type of cancer, and type of platin. We also collected information about the time point of diagnosis in each study, and whether they referred to acute toxicity or cumulative effect after completion of all cycles of chemotherapy. Papers referring to symptoms during chemotherapy without specifying the time point (such as which cycle) were not considered for analysis.

\section{Statistical Analyses}

A database was developed using IBM SPSS Statistics software (version 23.0 for Mac; IBM Corp., Armonk, NY, USA). Frequencies and descriptive statistics were examined for each variable. The primary outcome of interest was the proportion of patients who experienced pain because of PIPN.

\section{Compliance with Ethics Guidelines}

This article is based on previously conducted studies and does not involve any new studies of human or animal subjects performed by any of the authors.

\section{RESULTS}

\section{Search Results}

This search strategy resulted in the identification of 353 articles. A total of 282 articles were excluded during the eligibility assessment, and 

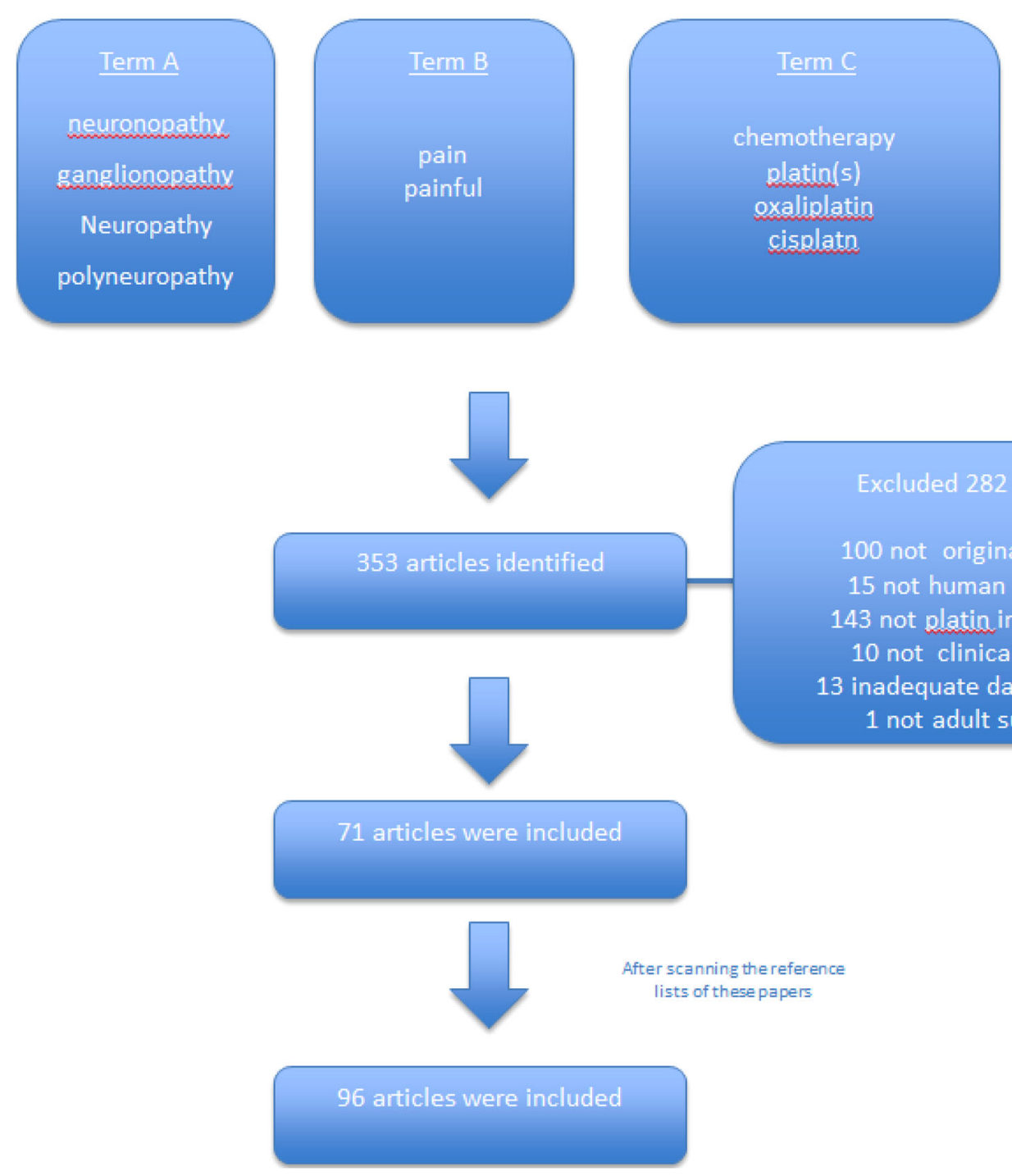

Excluded 282 articles

100 not original studies

15 not human subjects

143 not platin induced PN

10 not clinical studies

13 inadequate data provided

1 not adult subjects

Fig. 1 PRISMA chart

25 additional papers were identified by scanning the reference lists. Therefore, 96 papers met the inclusion criteria and were used for this review [9-104]. These studies were published between 1980 and 2017. Figure 1 illustrates the study selection process.

Full clinical and neurophysiological data were further extracted from 54 papers [29-82] involving a total of 8159 patients (49.8\% male) who received chemotherapy that included platins. The age of the patients ranged from 18 to 85 years (mean 65.9 years). The demographic and clinical characteristics of these patients are summarized in Table 1.
Forty-six papers provided data for the prevalence of PN in patients who received platins in their chemotherapeutic scheme. Of these, 22 papers reported PN during chemotherapy, 14 reported $\mathrm{PN}$ after completion of chemotherapy, and three specifically reported the acute toxic effects of oxaliplatin. Seven papers did not clearly specify the time point where PN occurred. The prevalence of established PN after chemotherapy was estimated at $56.5 \%$.

In 16 studies, patients received only platins, not combined with another neurotoxic chemotherapeutic agent. Of these, four papers 
Table 1 Description of studies included in the review

\begin{tabular}{ll}
\hline Parameter & Value \\
\hline Number of papers* & 54 \\
Total number of patients & 8159 \\
Number of patients per study, mean (SD) & $151.1(419.6)$ \\
Male: Female & $1: 1$ \\
Mean age, in years & 65.9 \\
Diagnosis of PN & \\
Questionnaires only (\%) & $12(22.2)$ \\
Nerve conduction studies (\%) & $3(5.6)$ \\
Quantitative sensory testing (\%) & $7(13.0)$ \\
Clinical examination (\%) & $8(14.8)$ \\
Not reported (\%) & $24(44.4)$ \\
Platin-induced PN (\%) & 73.3 \\
Painful PIPN (\%) & 45.8 \\
\hline
\end{tabular}

${ }^{*}$ Providing full clinical and neurophysiological data

$S D$ standard deviation, $P N$ peripheral neuropathy

reported PN during chemotherapy, eight reported PN after completion of chemotherapy, and three specifically reported the acute toxic effects of oxaliplatin. One paper did not clearly specify the time point at which PN occurred. The prevalence of neuropathic symptoms due to acute toxicity of oxaliplatin was estimated at 84.6\%, whereas established PN after chemotherapy with platins was estimated at $74.9 \%$. Of note, in only two studies-which provided data about the prevalence of PIPNwas PN confirmed with a full neurophysiological assessment.

Specifically regarding pain, the reported prevalence of pain due to acute toxicity of oxaliplatin was estimated at $55.6 \%$, whereas the reported prevalence of chronic peripheral neuropathic pain in PIPN was estimated at $49.2 \%$.

\section{Epidemiological Characteristics of PIPN}

A meta-analysis of 31 studies providing data from 4179 patients established that the prevalence of CIPN was $68.1 \%$ (95\% CI 57.7-78.4\%) when measured in the first month after chemotherapy completion, $60.0 \% \quad(95 \%$ CI $36.4-81.6 \%)$ at 3 months, and $30.0 \%$ (95\% CI $6.4-53.5 \%)$ at 6 months or more [9]. However, these figures refer to a variety of chemotherapeutic agents. Moreover, the diagnosis of the neuropathy was not made via nerve conduction studies (NCS) in all cases; in some studies, neuropathy was based only on quantitative sensory testing (QST), neurological examination, and/or questionnaires [9]. Among only those studies in which NCS or QST was used for assessment of neuropathy, the prevalence of CIPN was higher: 73.3\% (95\% CI 58.6-87.3) within 1 month of chemotherapy cessation, $70.1 \%$ (95\% CI 41.8-98.4) at 3 months, and $39.9 \%(95 \%$ CI $3.9-76.0)$ at 6 months or greater. A limitation of these figures, however, is that abnormal results obtained by QST without having performed NCS does not definitively establish the presence of $\mathrm{PN}$, and thus the above-mentioned percentages reflect the presence of neuropathic symptoms rather than CIPN.

Specifically concerning platins, the incidence of neuropathic symptoms for cisplatin ranged from $49 \%$ to $100 \%$, whereas carboplatin was reported to be less neurotoxic, with neuropathic symptoms observed in $13 \%$ to $42 \%$ of cases $[10,11]$. The presence of acute oxaliplatin-induced neuropathic symptoms has been reported in $85-95 \%$ of patients, and these symptoms have been observed in a chronic persistent form in approximately $16-21 \%$ of patients $[11,12,56]$.

\section{Risk Factors for PIPN}

Several risk factors have been associated with the development of painful PIPN. Wang et al. [32] reported that female sex, patient's level of functioning (assessed by the Eastern Cooperative Oncology Group performance status scale), body mass index (BMI), and baseline opioid use were associated with increased severity of oxaliplatin-induced peripheral neuropathy [32]. Attal et al. [58] revealed a significant relationship between the severity of acute signs and symptoms of oxaliplatin neurotoxicity after three cycles of chemotherapy and the occurrence and severity of chronic residual neuropathic symptoms as assessed by QST and the Neuropathic Pain Symptom Inventory (NPSI) after 1 year. 
Moreover, the duration of neuropathic symptoms was observed to increase as the cumulative dose of platin increased [69]. For example, Leonard et al. found that after the first cycle of chemotherapy, the median duration of dysesthesia was only 5 days, whereas it was 21 days in patients who received 12 cycles of chemotherapy. The median duration of paresthesia after cycle 1 was 7 days, but after cycle 12 was 21 days or longer [69]. Similarly, in many clinical trials sensory symptoms causing functional impairment have been found in only about $15 \%$ of patients after a cumulative dose of $780-850 \mathrm{mg} / \mathrm{m}^{2}$ but in $50 \%$ of patients at a cumulative dose of $1170 \mathrm{mg} / \mathrm{m}^{2}[13,14]$.

Specifically concerning carboplatin, Takemoto et al. [88] observed a greater visual analogue scale (VAS) score when it was combined with paclitaxel than with docetaxel; additionally, as the number of chemotherapy cycles increased, the carboplatin-paclitaxel-induced neuropathic symptoms became more severe.

Concerning cisplatin, Bezjak et al. [95] demonstrated that in lung cancer survivors, sensory cisplatin-induced neuropathic symptoms were a late effect of cisplatin, persisting for at least 9 months after chemotherapy and affecting quality of life. Similar symptoms have been reported as a late effect of cisplatin in long-term survivors of testicular cancer, and the cumulative dose of cisplatin has been reported to be a major risk factor for the development of toxicity [28].

Not all studies reported screening for pre-existing neuropathy prior to chemotherapy with platins. Also, not all studies reported having excluded patients with other common risk factors for PN such as diabetes, excessive alcohol intake, gluten sensitivity [105, 106], or hereditary neuropathies. Therefore, such comorbidities may have contributed to the development of PN.

\section{Predictors of PIPN}

Cold allodynia and hyperalgesia of the hands after three cycles of oxaliplatin treatment was found to be predictive of severe chronic neuropathy [58]. Among a range of cold stimuli, pain induced by a $20{ }^{\circ} \mathrm{C}$ stimulus to the hand had the highest predictive value with regard to development of severe chronic neuropathy. The severity of chronic neuropathy was also found to correlate with the duration of cold-evoked symptoms, the intensity of acute neuropathic symptoms, and the intensity of cold-evoked pain [58].

\section{Management}

Management of platin induced peripheral neuropathic pain includes pharmacological and non-pharmacological approaches [8].

\section{Antidepressants}

Venlafaxine, a serotonin and norepinephrine reuptake inhibitor, was effective in the management of acute neuropathic symptoms in a small series of patients receiving oxaliplatin [100]. Venlafaxine also showed promising preliminary evidence of clinical effectiveness of this combination against chronic neuropathic symptoms in oxaliplatin-induced PN [97]. According to the EFFOX study, complete relief of neuropathic symptoms induced by oxaliplatin was achieved in $31.3 \%$ of patients, which is a significantly higher percentage than the $5.3 \%$ achieved with placebo [91].

Duloxetine, another serotonin and norepinephrine reuptake inhibitor, was also found to be effective in oxaliplatin-induced painful neuropathy [55]. In an open-label study, Yang et al. demonstrated that duloxetine could be used effectively in low doses (i.e. $60 \mathrm{mg} /$ day) without impairment of renal or liver functionand importantly, without interfering with chemotherapy [55]. More recently, a large placebo-controlled randomized clinical trial showed that duloxetine was more effective than placebo in reducing the average PIPN pain score after a 5-week treatment period [101]. Overall, duloxetine has the largest volume of evidence supporting its use in the treatment of painful PIPN [107].

Nortriptyline, a tricyclic antidepressant, failed to demonstrate effectiveness for treating paresthesia or pain in cisplatin-induced neuropathic symptoms [98]. 


\section{Anticonvulsants}

Topiramate showed promising preliminary evidence of clinical effectiveness of this combination against chronic neuropathic symptoms in oxaliplatin-induced PN [97].

Carbamazepine, on the other hand, does not appear to be beneficial against acute oxaliplatin-induced painful neurotoxicity [99].

Research findings regarding the effectiveness of gabapentin for treating pain caused by PIPN remain controversial. In a phase III randomized, double-blind, placebo-controlled crossover trial, Rao et al. concluded that gabapentin failed to demonstrate any benefit [102], whereas an open-label study by Tsavaris et al. found that gabapentin monotherapy seemed to be well tolerated and useful for the management of chemotherapy-induced neuropathic pain [103]. However, both studies included patients with PN secondary to other chemotherapeutic agents in addition to platins. To date, no study has explored the efficacy of gabapentin alone in patients with PIPN.

\section{Opioids}

Liu et al. [89] reported that tramadol in combination with acetaminophen, administered in patients with colorectal or gastric adenocarcinoma, was effective in relieving oxaliplatin-induced peripheral neuropathic pain [89]. Interestingly, this study proposed that the A118G polymorphism of the mu-opioid receptor gene (OPRM1) was a possible mechanism for the reduced response to the combination of tramadol and acetaminophen [89], suggesting that management should be always be tailored to individual patient characteristics.

\section{Topical Drugs}

In an open-label study, Filipczak-Bryniarska et al. demonstrated that the high-dose capsaicin patch was effective in treating pain associated with oxaliplatin-induced neuropathy [104]. However, this finding should be interpreted with caution, given the limitations of the study design and small number of the participants.

\section{Non-Pharmacological Approaches}

There is some evidence that acupuncture may be beneficial for the treatment of PIPN. In a small case series, Donald et al. [87] reported that patients with oxaliplatin-induced painful neuropathy improved after acupuncture. Wong et al. [96] similarly described a small series of patients with symptoms of pain due to carboplatin-induced neuropathy who improved after acupuncture. A prospective pilot study by Hsieh et al. [30] showed that laser acupuncture relieved both cold and mechanical allodynia induced by oxaliplatin in gastrointestinal cancer survivors. To date, however, no large randomized controlled trial has been conducted to confirm the effectiveness of acupuncture in managing pain in PIPN. Therefore, the current evidence is weak.

Cunningham et al. [90] reported a case of almost complete resolution of the tingling, numbness, and pain of cisplatin-induced neuropathy with manual therapy (massage) in a patient with stage III esophageal adenocarcinoma. However, as this was based on a single case, this finding should be interpreted with extreme caution.

Henke et al. [84] reported that strength and endurance training in patients receiving platinum-based chemotherapy for lung cancer was effective in managing pain. The authors thus suggested that lung cancer patients should receive enhanced physical activity intervention during palliative chemotherapy.

\section{Diagnosing and Monitoring PIPN}

\section{Large Fiber Neuropathy}

The gold standard for diagnosing a large fiber neuropathy is NCS. Although centers have many different means of neurophysiologically determining the presence of PN, sensory conduction studies of sural and radial nerves are recommended for the diagnosis of mild, predominantly sensory axonal neuropathy [108]. This should be complemented with at least one motor study, commonly of the tibial nerve, to confirm motor involvement $[109,110]$. In the case of PIPN, however, the neuropathy is sensory, affecting the dorsal root ganglia. In a 
sensory ganglionopathy, asymmetrical sensory nerve action potentials (SNAPs) or complete absence of SNAPs should be expected [111, 112].

\section{Small Fiber Neuropathy}

Patients often complain of disabling symptoms such as a burning sensation in the soles or the fingertips, which is a common manifestation of small fiber neuropathy (SFN). Nerve conduction studies assess only large fibers, and therefore, SFN cannot be excluded if NCS are normal.

The gold standard for a diagnosis of SFN is skin biopsy; however, this is an invasive technique and is thus usually avoided. QST is commonly used for assessment of SFN, but this is subjective. Alternatively, nerve morphology can be rapidly assessed using in vivo corneal confocal microscopy. This technique has been used for the detection of various types of neuropathy, including small fiber neuropathy [15]. Ferdousi et al. [35] showed that corneal confocal microscopy was effective in detecting small fiber neuropathy by a marked reduction in corneal nerve morphological parameters in patients with upper gastrointestinal cancer and oxaliplatin- or cisplatin-induced neuropathy.

\section{Questionnaires}

Several questionnaires have been used for the detection and assessment of PIPN. Particular interest has been focused on the development and validation of questionnaires regarding quality of life in patients with CIPN.

The European Organisation for Research and Treatment of Cancer Quality of Life Questionnaire C30 (EORTC QLQ-C30), designed to assess quality of life for cancer patients, is widely used and consists of 30 items comprising five functional scales (physical, role, emotional, cognitive, and social), global health status, and nine symptom scales and single items (fatigue, nausea and vomiting, pain, dyspnea, insomnia, appetite loss, constipation, diarrhea, and financial difficulties. It is also supplemented with specific modules for the different cancer types [16, 17, 83, 84, 95].

The EORTC QLQ-CIPN20 is a quality-of-life questionnaire developed to elicit patient experience of symptoms and functional limitations related to CIPN. It contains 20 items assessing sensory, motor, and autonomic symptoms $[18,86]$. The CIPN20 can assess frequency and severity of painful CIPN in a wide range of oncology patient populations.

The L-BASIC [location-based assessment of sensory symptoms in cancer] instrument uses location-specific ratings of sensory symptoms in the cancer population [94]. It is structured such that patients provide a numeric score and an adjectival description for any sensory symptoms, including both pain and neuropathic sensations, present in each of 10 predefined body areas [94].

The Rasch-built Overall Disability Scale for CIPN (CIPN-R-ODS) is a Rasch-built disease-specific interval measure suitable for detecting disability and levels of activity and participation in patients with stable disease [85].

The Functional Assessment of Cancer Therapy/Gynecologic Oncology Group-Neurotoxicity (FACT/GOG-Ntx) questionnaire is the Functional Assessment of Cancer Therapy-General (FACT-G) instrument plus an 11-item subscale (Ntx subscale) [19]. It is a chemotherapy treatment effect-specific measurement tool used to evaluate the severity and impact of CIPN symptoms on functional status and health-related quality of life [19]. Questions on the Ntx subscale include the feeling of generalized weakness, numbness or tingling in the hands or feet, and difficulty with fine motor movements $[19,20]$.

The Total Neuropathy Score (TNS) was initially designed to evaluate diabetic neuropathy [21] and was later validated in patients with CIPN [22]. The TNS includes objective measures, such as pin prick, vibration threshold, and nerve conduction studies, combined with subjective report of sensory, motor, and autonomic items, and the instrument has been tested in a variety of tumor types [22-24, 93].

The chemotherapy-induced neuropathy-specific Neuropathic Pain Scale (NPS-CIN) is a six-item scale used to assess CIPN and related neuropathic pain severity $[25,92,93]$.

The Patient Neurotoxicity Questionnaire, comprising two items, defines the incidence 
and severity of sensory and motor disturbances [26].

The Chemotherapy-Induced Peripheral Neuropathy Assessment Tool (CIPNAT) contains 36 items that evaluate the occurrence, severity, distress, and frequency of nine neuropathic symptoms, along with 14 items that evaluate neuropathic interference with activities [27].

\section{CONCLUSION}

This systematic review has identified the following key points:

1. $\mathrm{PN}$ is a common complication in patients receiving platins in their chemotherapeutic regime.

2. PIPN can be particularly painful. Acute toxicity occurs only with oxaliplatin. However, in a significant proportion of patients receiving platins, the pain persists and becomes chronic.

3. There is significant heterogeneity in the methods used to diagnose PN. In many studies, patients were diagnosed based only on questionnaires or clinical examination. Although the use of questionnaires may be adequate for characterizing and monitoring neuropathic symptoms, the gold standard for accurate diagnosis of an established peripheral neuropathy-from a neurological point of view-is NCS. Ideally, this should be performed as a baseline, before the chemotherapy, and should be repeated at the end or when symptoms occur. QST alone is not sufficient for establishing a diagnosis of $\mathrm{PN}$, as it is not objective, and its role is more as an indicator of small fiber involvement; therefore, QST should be complemented with NCS.

4. Small fiber neuropathy is gaining increasing attention in clinical practice; however, further studies are needed in patients receiving platins, as the neuropathic pain that patients experience during chemotherapy with platins is likely often secondary to small fiber involvement, with no involvement of the large fibers.

\section{ACKNOWLEDGEMENTS}

Funding. No funding or sponsorship was received for this study or publication of this article.

Authorship. All named authors meet the International Committee of Medical Journal Editors (ICMJE) criteria for authorship of this manuscript, take responsibility for the integrity of the work as a whole, and have given final approval for the version to be published.

Disclosures. Vasiliki Brozou, Athina Vadalouca, and Panagiotis Zis have nothing to disclose.

Compliance with Ethics Guidelines. This article is based on previously conducted studies and does not involve any new studies of human or animal subjects performed by any of the authors.

Data Availability. The data sets generated and/or analyzed during the current study are available from the corresponding author on reasonable request.

Open Access. This article is distributed under the terms of the Creative Commons Attribution-NonCommercial 4.0 International License (http://creativecommons.org/licenses/ by-nc/4.0/), which permits any noncommercial use, distribution, and reproduction in any medium, provided you give appropriate credit to the original author(s) and the source, provide a link to the Creative Commons license, and indicate if changes were made.

\section{REFERENCES}

1. Martyn CN, Hughes RA. Epidemiology of peripheral neuropathy. J Neurol Neurosurg Psychiatry. 1997;62(4):310-8.

2. Zis P, Sarrigiannis PG, Rao DG, Hewamadduma C, Hadjivassiliou M. Chronic idiopathic axonal polyneuropathy: a systematic review. J Neurol. 2016;263(10):1903-10. 
3. Zis P, Varrassi G. Painful peripheral neuropathy and cancer. Pain Ther. 2017. https://doi.org/10.1007/ s40122-017-0077-2.

4. Marchettini P, Formaglio F, Lacerenza M. Iatrogenic painful neuropathic complications of surgery in cancer. Acta Anaesthesiol Scand. 2001;45(9):1090-4.

5. Hershman DL, Lacchetti C, Dworkin RH, Lavoie Smith EM, Bleeker J, Cavaletti G, Chauhan C, Gavin P, Lavino A, Lustberg MB, Paice J, Schneider B, Smith ML, Smith T, Terstriep S, Wagner-Johnston N, Bak K, Loprinzi CL, American Society of Clinical Oncology. Prevention and management of chemotherapy-induced peripheral neuropathy in survivors of adult cancers: American Society of Clinical Oncology clinical practice guideline. J Clin Oncol. 2014;32(18):1941-67.

6. Zis P, Paladini A, Piroli A, McHugh PC, Varrassi G, Hadjivassiliou M. Pain as a first manifestation of paraneoplastic neuropathies: a systematic review and meta-analysis. Pain Ther. 2017. https://doi.org/ 10.1007/s40122-017-0076-3.

7. Zis P, Rao DG, Wagner BE, Nicholson-Goult L, Hoggard N, Hadjivassiliou M. Cerebellar ataxia and sensory ganglionopathy associated with light-chain myeloma. Cerebellum Ataxias. 2017;5(4):1. https:// doi.org/10.1186/s40673-016-0060-4.

8. Vadalouca A, Raptis E, Moka E, Zis P, Sykioti P, Siafaka I. Pharmacological treatment of neuropathic cancer pain: a comprehensive review of the current literature. Pain Pract. 2012;12(3):219-511.

9. Seretny M, Curie GL, Sena ES, Ramnarine S, Grant R, MacLeod MR, Colvin LA, Fallon M. Incidence, prevalence, and predictors of chemotherapy-induced peripheral neuropathy: a systematic review and meta-analysis. Pain. 2014;155(12):2461-7.

10. Mollman JE, Glover DJ, Hogan WM, Furman RE. Cisplatin neuropathy. Risk factors, prognosis, and protection by WR-2721. Cancer. 1988;61:2192-5.

11. Hausheer FH, Schilsky RL, Bain S, Berghorn EJ, Lieberman F. Diagnosis, management, and evaluation of chemotherapy-induced peripheral neuropathy. Semin Oncol. 2006;33(1):15-49.

12. Storey DJ, Sakala M, McLean CM, Phillips HA, Dawson LK, Wall LR, Fallon MT, Clive S. Capecitabine combined with oxaliplatin (CapOx) in clinical practice: How significant is peripheral neuropathy? Ann Oncol. 2010;21(8):1657-61.

13. de Gramont A, Figer A, Seymour M, Homerin M, Hmissi A, Cassidy J, Boni C, Cortes-Funes H, Cervantes A, Freyer G, Papamichael D, Le Bail N, Louvet C, Hendler D, de Braud F, Wilson C, Morvan F,
Bonetti A. Leucovorin and fluorouracil with or without oxaliplatin as first-line treatment in advanced colorectal cancer. J Clin Oncol. 2000;18:2938-47.

14. Brienza S, Vignoud J, Itzakhi M, Krikorian A: 933 oxaliplatin $\left(\mathrm{L}-\mathrm{OHP}^{\circledR}\right)$ : global safety in 682 patients (PTS). Proc Am Soc Clin Oncol. 1995;14:209.

15. Tavakoli M, Marshall A, Pitceathly R, Gow D, Roberts ME, Malik RA. Corneal confocal microscopy: a novel means to detect nerve fibre damage in idiopathic small fibre neuropathy. Exp Neurol. 2010;223(1):245-50.

16. Mols F, Beijers T, Lemmens V, van den Hurk CJ, Vreugdenhil G, van de Poll-Franse LV. Chemotherapy-induced neuropathy and its association with quality of life among 2- to 11-year colorectal cancer survivors: results from the population-based PROFILES registry. J Clin Oncol. 2013;31(21):2699-707.

17. Dearnaley DP, Fossa SD, Kaye SB, Cullen MH, Harland SJ, Sokal MP, Graham JD, Roberts JT, Mead GM, Williams MV, Cook PA, Stenning SP. Adjuvant bleomycin, vincristine and cisplatin (BOP) for high-risk stage I non-seminomatous germ cell tumours: a prospective trial (MRC TE17), MRC Testicular Tumour Working Party. Br J Cancer. 2005;92(12):2107-13.

18. Postma TJ, Aaronson NK, Heimans JJ, Muller MJ, Hildebrand JG, Delattre JY, Hoang-Xuan K, Lantéri-Minet M, Grant R, Huddart R, Moynihan C, Maher J, Lucey R. The development of an EORTC quality of life questionnaire to assess chemotherapyinduced peripheral neuropathy: the QLQ-CIPN20. Eur J Cancer. 2005;41:1135-9.

19. Calhoun EA, Welshman EE, Chang $\mathrm{CH}$, Lurain JR, Fishman DA, Hunt TL, Cella D. Psychometric evaluation of the Functional Assessment of Cancer Therapy/Gynecologic Oncology Group Neurotoxicity (Fact/GOG-Ntx) questionnaire for patients receiving systemic chemotherapy. Int $\mathrm{J}$ Gynecol Cancer. 2003;13(6):741-8.

20. Huang HQ, Brady MF, Cella D, Fleming G. Validation and reduction of FACT/GOG-Ntx subscale for platinum/paclitaxel-induced neurologic symptoms: a gynecologic oncology group study. Int J Gynecol Cancer. 2007; 17:387-93.

21. Cornblath DR, Chaudhry V, Carter K, Lee D, Seysedadr M, Miernicki M, Joh T. Total neuropathy score: validation and reliability study. Neurology. 1999;10:1660-4.

22. Cavaletti G, Bogliun G, Marzorati L, Zincone A, Piatti M, Colombo N, Parma G, Lissoni A, Fei F, Cundari S, Zanna C. Grading of chemotherapy 
induced peripheral neurotoxicity using the Total Neuropathy scale. Neurology. 2003;61(9):1297-300.

23. Cavaletti G, Frigeni B, Lanzani F, Piatti M, Rota S, Briani C, Zara G, Plasmati R, Pastorelli F, Caraceni A, Pace A, Manicone M, Lissoni A, Colombo N, Bianchi G, Zanna C. The Total Neuropathy Score as an assessment tool for grading the course of chemotherapy-induced peripheral neurotoxicity: Comparison with the National Cancer Institute Common Toxicity Scale. J Peripher Nerv Syst. 2007;12(3):210-5.

24. Cavaletti G, Jann S, Pace A, Plasmati R, Siciliano G, Briani C, Cocito D, Padua L, Ghiglione E, Manicone M, Giussani G. Multi-center assessment of the Total Neuropathy Score for chemotherapy-induced peripheral neurotoxicity. J Peripher Nerv Syst. 2006;11(2):135-41.

25. Wampler MA, Miaskowski C, Hamel K, Byl N, Rugo $\mathrm{H}$, Topp LS. The modified total neuropathy score: a clinically feasible and valid measure of taxane-induced peripheral neuropathy in women with breast cancer. Support Oncol. 2006;4(8):W9-16.

26. Shimozuma K, Ohashi Y, Takeuchi A, Aranishi T, Morita S, Kuroi K, Ohsumi S, Makino H, Mukai H, Katsumata N, Sunada Y, Watanabe T, Hausheer FH. Feasibility and validity of the patient neurotoxicity questionnaire during taxane chemotherapy in a phase III randomized trial in patients with breast cancer: N-SAS BC 02. Support Care Cancer. 2009;17:1483-91.

27. Tofthagen CS, McMillan SC, Kip KE. Development and psychometric evaluation of the chemotherapy-induced peripheral neuropathy assessment tool. Cancer Nurs. 2011;34:E10-20.

28. Bokemeyer C, Berger C, Kuczyk M, Schmoll HJ. Evaluation of long-term toxicity after chemotherapy for testicular cancer. J Clin Oncol. 1996;14(11):2923-32.

29. Andriamamonjy M, Delmotte JB, Savinelli F, Beaussier H, Coudoré F. Quantification of chronic oxaliplatin-induced hypesthesia in two areas of the hand. J Clin Neurophysiol. 2017;34(2):126-31.

30. Hsieh YL, Chou LW, Hong SF, Chang FC, Tseng SW, Huang CC, Yang $\mathrm{CH}$, Yang CC, Chiu WF. Laser acupuncture attenuates oxaliplatin-induced peripheral neuropathy in patients with gastrointestinal cancer: a pilot prospective cohort study. Acupunct Med. 2016;34(5):398-400.

31. Zhu T, Liu CL, Zhang YF, Liu YH, Xu FP, Zu J, Zhang GC, Li XR, Liao N. Wang K.A phase II trial of dose-dense (biweekly) paclitaxel plus carboplatin as neoadjuvant chemotherapy for operable breast cancer. Breast Cancer Res Treat. 2016;156(1):117-24.

32. Wang XS, Shi Q, Dougherty PM, Eng C, Mendoza TR, Williams LA, Fogelman DR, Cleeland CS. Prechemotherapy touch sensation deficits predict oxaliplatin-induced neuropathy in patients with colorectal cancer. Oncology. 2016;90(3):127-35.

33. Nagao S, Iwasa N, Kurosaki A, Nishikawa T, Hanaoka T, Hasegawa K, Fujiwara K. The efficacy of low-dose paclitaxel added to combination chemotherapy of carboplatin and gemcitabine or pegylated liposomal doxorubicin. Int J Gynecol Cancer. 2016;26(3):443-8.

34. Ventzel L, Jensen AB, Jensen AR, Jensen TS, Finnerup NB. Chemotherapy-induced pain and neuropathy: a prospective study in patients treated with adjuvant oxaliplatin or docetaxel. Pain. 2016;157(3):560-8.

35. Ferdousi M, Azmi S, Petropoulos IN, Fadavi $H$, Ponirakis G, Marshall A, Tavakoli M, Malik I, Mansoor W, Malik RA. Corneal confocal microscopy detects small fibre neuropathy in patients with upper gastrointestinal cancer and nerve regeneration in chemotherapy induced peripheral neuropathy. PLoS One. 2015;10(10):e0139394.

36. Ochenduszko S, Puskulluoglu M, Konopka K, Fijorek K, Urbanczyk K, Budzynski A, Matlok M, Lazar A, Sinczak-Kuta A, Pedziwiatr M, Krzemieniecki K. Comparison of efficacy and safety of first-line palliative chemotherapy with EOX and mDCF regimens in patients with locally advanced inoperable or metastatic HER2-negative gastric or gastroesophageal junction adenocarcinoma: a randomized phase 3 trial. Med Oncol. 2015;32(10):242.

37. Pachman DR, Qin R, Seisler DK, Smith EM, Beutler AS, Ta LE, Lafky JM, Wagner-Johnston ND, Ruddy KJ, Dakhil S, Staff NP, Grothey A, Loprinzi CL. Clinical course of oxaliplatin-induced neuropathy: results from the randomized phase III trial N08CB (alliance). J Clin Oncol. 2015;33(30):3416-22.

38. Makielski RJ, Lubner SJ, Mulkerin DL, Traynor AM, Groteluschen D, Eickhoff J, LoConte NK. A phase II study of sorafenib, oxaliplatin, and 2 days of high-dose capecitabine in advanced pancreas cancer. Cancer Chemother Pharmacol. 2015;76(2):317-23.

39. Hu XC, Zhang J, Xu BH, Cai L, Ragaz J, Wang ZH, Wang BY, Teng YE, Tong ZS, Pan YY, Yin YM, Wu CP, Jiang ZF, Wang XJ, Lou GY, Liu DG, Feng JF, Luo JF, Sun K, Gu YJ, Wu J, Shao ZM. Cisplatin plus gemcitabine versus paclitaxel plus gemcitabine as first-line therapy for metastatic triple-negative breast cancer (CBCSG006): a randomised, 
open-label, multicentre, phase 3 trial. Lancet Oncol. 2015;16(4):436-46.

40. Ezendam NP, Pijlman B, Bhugwandass C, Pruijt JF, Mols F, Vos MC, Pijnenborg JM, van de Poll-Franse LV. Chemotherapy-induced peripheral neuropathy and its impact on health-related quality of life among ovarian cancer survivors: results from the population-based PROFILES registry. Gynecol Oncol. 2014;135(3):510-7.

41. Padman S, Lee J, Kumar R, Slee M, Hakendorf P, Richards A, Koczwara B, Kichenadasse G, Sukumaran S, Roy A, Vatandoust S, Karapetis CS. Late effects of oxaliplatin-induced peripheral neuropathy (LEON)-cross-sectional cohort study of patients with colorectal cancer surviving at least 2 years. Support Care Cancer. 2015;23(3):861-9.

42. Du J, Hu C, Zhang Y, Hu B, Wang F, Zhang Y. A retrospective study of paclitaxel combining nedaplatin chemotherapy for esophageal cancer. Anticancer Drugs. 2015;26(1):101-5.

43. de Carvalho Barbosa M, Kosturakis AK, Eng C, Wendelschafer-Crabb G, Kennedy WR, Simone DA, Wang XS, Cleeland CS, Dougherty PM. A quantitative sensory analysis of peripheral neuropathy in colorectal cancer and its exacerbation by oxaliplatin chemotherapy. Cancer Res. 2014;74(21):5955-62.

44. Taylor SE, Beck TL, Krivak TC, Zorn KK, Kelley JL, Edwards RP. Oxaliplatin salvage for recurrent ovarian cancer: a single institution's experience in patient populations with platinum resistant disease or a history of platinum hypersensitivity. Gynecol Oncol. 2014;134(1):68-72.

45. Leal AD, Qin R, Atherton PJ, Haluska P, Behrens RJ, Tiber CH, Watanaboonyakhet P, Weiss M, Adams PT, Dockter TJ, Loprinzi CL. Alliance for Clinical Trials in Oncology North Central Cancer Treatment Group/Alliance trial N08CA-the use of glutathione for prevention of paclitaxel/carboplatin-induced peripheral neuropathy: a phase 3 randomized, double-blind, placebo-controlled study. Cancer. 2014;120(12):1890-7.

46. Krøigård T, Schrøder HD, Qvortrup C, Eckhoff L, Pfeiffer P, Gaist D, Sindrup SH. Characterization and diagnostic evaluation of chronic polyneuropathies induced by oxaliplatin and docetaxel comparing skin biopsy to quantitative sensory testing and nerve conduction studies. Eur J Neurol. 2014;21(4):623-9.

47. Guo Y, Jones D, Palmer JL, Forman A, Dakhil SR, Velasco MR, Weiss M, Gilman P, Mills GM, Noga SJ, Eng C, Overman MJ, Fisch MJ. Oral alpha-lipoic acid to prevent chemotherapy-induced peripheral neuropathy: a randomized, double-blind, placebo-controlled trial. Support Care Cancer. 2014;22(5):1223-31.

48. Griffith KA, Couture DJ, Zhu S, Pandya N, Johantgen ME, Cavaletti G, Davenport JM, Tanguay LJ, Choflet A, Milliron T, Glass E, Gambill N, Renn CL, Dorsey SG. Evaluation of chemotherapy-induced peripheral neuropathy using current perception threshold and clinical evaluations. Support Care Cancer. 2014;22(5):1161-9.

49. Mols F, Beijers T, Lemmens V, van den Hurk CJ, Vreugdenhil G, van de Poll-Franse LV. Chemotherapy-induced neuropathy and its association with quality of life among 2- to 11-year colorectal cancer survivors: results from the population-based PROFILES registry. J Clin Oncol. 2013;31(21):2699-707.

50. Sohal DP, Metz JM, Sun W, Giantonio BJ, Plastaras JP, Ginsberg G, Kochman ML, Teitelbaum UR, Harlacker K, Heitjan DF, Feldman MD, Drebin JA, O'Dwyer PJ. Toxicity study of gemcitabine, oxaliplatin, and bevacizumab, followed by 5-fluorouracil, oxaliplatin, bevacizumab, and radiotherapy, in patients with locally advanced pancreatic cancer. Cancer Chemother Pharmacol. 2013;71(6):1485-91.

51. Sun V, Otis-Green S, Morgan R, Wakabayashi M, Hakim A, Callado ME, Yang E, Ferrell B, Grant M. Toxicities, complications, and clinical encounters during intraperitoneal chemotherapy in 17 women with ovarian cancer. Eur J Oncol Nurs. 2013;17(3):375-80.

52. Nielsen DL, Nørgaard H, Vestermark LW, Pfeiffer P, Jensen BK, Nelausen KM, Bergenfeldt M, Hermann $\mathrm{KL}$, Jensen BV. Intrahepatic and systemic therapy with oxaliplatin combined with capecitabine in patients with hepatic metastases from breast cancer. Breast. 2012;21(4):556-61.

53. Reeves BN, Dakhil SR, Sloan JA, Wolf SL, Burger KN, Kamal A, Le-Lindqwister NA, Soori GS, Jaslowski AJ, Kelaghan J, Novotny PJ, Lachance DH, Loprinzi CL. Further data supporting that paclitaxel-associated acute pain syndrome is associated with development of peripheral neuropathy: north Central Cancer Treatment Group trial N08C1. Cancer. 2012;118(20):5171-8.

54. Stavraka C, Ford A, Ghaem-Maghami S, Crook T, Agarwal R, Gabra H, Blagden S. A study of symptoms described by ovarian cancer survivors. Gynecol Oncol. 2012;125(1):59-64.

55. Yang YH, Lin JK, Chen WS, Lin TC, Yang SH, Jiang JK, Chang SC, Lan YT, Lin CC, Yen CC, Tzeng CH, Wang WS, Chiang HL, Teng CJ, Teng HW. Duloxetine improves oxaliplatin-induced neuropathy in patients with colorectal cancer: an open-label pilot study. Support Care Cancer. 2012;20(7):1491-7. 
56. Tofthagen C, McAllister RD, McMillan SC. Peripheral neuropathy in patients with colorectal cancer receiving oxaliplatin. Clin J Oncol Nurs. 2011;15(2):182-8.

57. Zweifel M, Jayson GC, Reed NS, Osborne R, Hassan B, Ledermann J, Shreeves G, Poupard L, Lu SP, Balkissoon J, Chaplin DJ, Rustin GJ. Phase II trial of combretastatin A4 phosphate, carboplatin, and paclitaxel in patients with platinum-resistant ovarian cancer. Ann Oncol. 2011;22(9):2036-41.

58. Attal N, Bouhassira D, Gautron M, Vaillant JN, Mitry E, Lepère C, Rougier P, Guirimand F. Thermal hyperalgesia as a marker of oxaliplatin neurotoxicity: a prospective quantified sensory assessment study. Pain. 2009;144(3):245-52.

59. Allegra CJ, Yothers G, O'Connell MJ, Sharif S, Colangelo LH, Lopa SH, Petrelli NJ, Goldberg RM, Atkins JN, Seay TE, Fehrenbacher L, O'Reilly S, Chu L, Azar CA, Wolmark N. Initial safety report of NSABP C-08: a randomized phase III study of modified FOLFOX6 with or without bevacizumab for the adjuvant treatment of patients with stage II or III colon cancer. J Clin Oncol. 2009;27(20):3385-90.

60. Carlomagno C, Farella A, Bucci L, D'Armiento FP, Pesce G, Pepe S, Cannella L, Pacelli R, De Stefano A, Solla R, D'Armiento MR, De Placido S. Neo-adjuvant treatment of rectal cancer with capecitabine and oxaliplatin in combination with radiotherapy: a phase II study. Ann Oncol. 2009;20(5):906-12.

61. Chin SN, Pinto V, Rosen B, Oza A, Dodge J, Murphy J, Mackay H. Evaluation of an intraperitoneal chemotherapy program implemented at the Princess Margaret Hospital for patients with epithelial ovarian carcinoma. Gynecol Oncol. 2009;112(3):450-4.

62. Suzuki R, Yamamoto M, Saka H, Taniguchi H, Shindoh J, Tanikawa Y, Nomura F, Gonda H, Imaizumi K, Hasegawa Y, Shimokata K. A phase II study of carboplatin and paclitacel with meloxicam. Lung Cancer. 2009;63(1):72-6.

63. Zhu X, Leaw J, Gu W, Qian Y, Du H, Wang B, Hong $X$, Yin J. Phase II clinical trial of advanced and metastatic gastric cancer based on continuous infusion of 5-fluorouracil combined with epirubicin and oxaliplatin. J Cancer Res Clin Oncol. 2008;134(9):929-36.

64. Boige V, Malka D, Elias D, Castaing M, De Baere T, Goere D, Dromain C, Pocard M, Ducreux M. Hepatic arterial infusion of oxaliplatin and intravenous LV5FU2 in unresectable liver metastases from colorectal cancer after systemic chemotherapy failure. Ann Surg Oncol. 2008;15(1):219-26.
65. Binder A, Stengel M, Maag R, Wasner G, Schoch R, Moosig F, Schommer B, Baron R. Pain in oxaliplatin-induced neuropathy-sensitisation in the peripheral and central nociceptive system. Eur J Cancer. 2007;43(18):2658-63.

66. Land SR, Kopec JA, Cecchini RS, Ganz PA, Wieand HS, Colangelo LH, Murphy K, Kuebler JP, Seay TE, Needles BM, Bearden JD 3rd, Colman LK, Lanier KS, Pajon ER Jr, Cella D, Smith RE, O'Connell MJ, Costantino JP, Wolmark N. Neurotoxicity from oxaliplatin combined with weekly bolus fluorouracil and leucovorin as surgical adjuvant chemotherapy for stage II and III colon cancer: NSABP C-07. J Clin Oncol. 2007;25(16):2205-11.

67. Dragovich T, Mendelson D, Kurtin S, Richardson K, Von Hoff D, Hoos A. A Phase 2 trial of the liposomal DACH platinum L-NDDP in patients with therapy-refractory advanced colorectal cancer. Cancer Chemother Pharmacol. 2006;58(6):759-64.

68. Hu JB, Sun XN, Yang QC, Xu J, Wang Q, He C. Three-dimensional conformal radiotherapy combined with FOLFOX4 chemotherapy for unresectable recurrent rectal cancer. World J Gastroenterol. 2006;12(16):2610-4.

69. Leonard GD, Wright MA, Quinn MG, Fioravanti S, Harold N, Schuler B, Thomas RR, Grem JL. Survey of oxaliplatin-associated neurotoxicity using an interview-based questionnaire in patients with metastatic colorectal cancer. BMC Cancer. 2005;16(5):116.

70. Dearnaley DP, Fossa SD, Kaye SB, Cullen MH, Harland SJ, Sokal MP, Graham JD, Roberts JT, Mead GM, Williams MV, Cook PA, Stenning SP, MRC Testicular Tumour Working Party. Adjuvant bleomycin, vincristine and cisplatin (BOP) for high-risk stage I non-seminomatous germ cell tumours: a prospective trial (MRC TE17). $\mathrm{Br} \mathrm{J}$ Cancer. 2005;92(12):2107-13.

71. Fujiwara K, Suzuki S, Ishikawa H, Oda T, Aotani E, Kohno I. Preliminary toxicity analysis of intraperitoneal carboplatin in combination with intravenous paclitaxel chemotherapy for patients with carcinoma of the ovary, peritoneum, or fallopian tube. Int J Gynecol Cancer. 2005;15(3):426-31.

72. Marsland TA, Garfield DH, Khan MM, Look RM, Boehm KA, Asmar L. Sequential versus concurrent paclitaxel and carboplatin for the treatment of advanced non-small cell lung cancer in elderly patients and patients with poor performance status: results of two Phase II, multicenter trials. Lung Cancer. 2005;47(1):111-20.

73. Sabbatini P, Aghajanian C, Leitao M, Venkatraman E, Anderson S, Dupont J, Dizon D, O'Flaherty C, Bloss J, Chi D, Spriggs D. Intraperitoneal cisplatin 
with intraperitoneal gemcitabine in patients with epithelial ovarian cancer: results of a phase I/II Trial. Clin Cancer Res. 2004;10(9):2962-7.

74. Yasufuku T, Shigemura K, Matsumoto O, Arakawa S, Fujisawa M. Combination chemotherapy with weekly paclitaxel or docetaxel, carboplatin, and estramustine for hormone-refractory prostate cancer. J Infect Chemother. 2010;16(3):200-5.

75. Martinez-Monge R, Jurado M, Aristu JJ, Moreno M, Cambeiro M, Perez-Ochoa A, Lopez-Garcia G, Alcazar JL. Intraoperative electron beam radiotherapy during radical surgery for locally advanced and recurrent cervical cancer. Gynecol Oncol. 2001;82(3):538-43.

76. Kern W, Beckert B, Lang N, Stemmler J, Beykirch M, Stein J, Goecke E, Waggershauser T, Braess J, Schalhorn A, Hiddemann W. Phase I and pharmacokinetic study of hepatic arterial infusion with oxaliplatin in combination with folinic acid and 5-fluorouracil in patients with hepatic metastases from colorectal cancer. Ann Oncol. 2001;12(5):599-603.

77. Greenberg HS, Chamberlain MC, Glantz MJ, Wang S. Adult medulloblastoma: multiagent chemotherapy. Neuro Oncol. 2001;3(1):29-34.

78. Mulatero C, McClaren BR, Mason M, Oliver RT, Gallagher CJ. Evidence for a schedule-dependent deleterious interaction between paclitaxel, vinblastine and cisplatin (PVC) in the treatment of advanced transitional cell carcinoma. Br J Cancer. 2000;83(12):1612-6.

79. Makhija S, Sabbatini P, Aghajanian C, Venkatraman E, Spriggs DR, Barakat R. Intraperitoneal cisplatin and intravenous paclitaxel in the treatment of epithelial ovarian cancer patients with a positive second look. Gynecol Oncol. 2000;79(1):28-32.

80. Plaxe SC, Braly PS, Freddo JL, McClay E, Christen RD, Kirmani S, Kim S, Heath D, Howell SB. Phase I and pharmacokinetic study of intraperitoneal ormaplatin. Gynecol Oncol. 1993;51(1):72-7.

81. Greenspan A, Treat J. Peripheral neuropathy and low dose cisplatin. Am J Clin Oncol. 1988;11(6):660-2.

82. Sugiyama T, Okamoto A, Enomoto T, Hamano T, Aotani E, Terao Y, Suzuki N, Mikami M, Yaegashi N, Kato K, Yoshikawa H, Yokoyama Y, Tanabe H, Nishino K, Nomura H, Kim J, Kim BG, Pignata S, Alexandre J, Green J, Isonishi S, Terauchi F, Fujiwara $\mathrm{K}$, Aoki D. Randomized phase III trial of irinotecan plus cisplatin compared with paclitaxel plus carboplatin as first-line chemotherapy for ovarian clear cell carcinoma: JGOG3017/GCIG Trial. J Clin Oncol. 2016;34(24):2881-7.
83. Brotto L, Brundage $M$, Hoskins P, Vergote I, Cervantes A, Casado HA, Poveda A, Eisenhauer E, Dongsheng Tu. Randomized study of sequential cisplatin-topotecan/carboplatin-paclitaxel versus carboplatin-paclitaxel: effects on quality of life. Support Care Cancer. 2014;22:95-101.

84. Henke CC, Cabri J, Fricke L, Pankow W, Kandilakis G, Feyer PC, de Wit M. Strength and endurance training in the treatment of lung cancer patients in stages IIIA/IIIB/IV. Support Care Cancer. 2014;22:95-101.

85. Binda D, Vanhoutte EK, Cavaletti G, Cornblath DR, Postma TJ, Frigeni B, Alberti P, Bruna J, Velasco R, Argyriou AA, Kalofonos HP, Psimaras D, Ricard D, Pace A, Galiè E, Briani C, Dalla Torre C, Lalisang RI, Boogerd W, Brandsma D, Koeppen S, Hense J, Storey D, Kerrigan S, Schenone A, Fabbri S, Rossi E, Valsecchi MG, Faber CG, Merkies IS, CI-PeriNomS study group, Galimberti S, Lanzani F, Mattavelli L, Piatti ML, Bidoli P, Cazzaniga M, Cortinovis D, Lucchetta M, Campagnolo M, Bakkers M, Brouwer B, Boogerd W, Grant R, Reni L, Piras B, Pessino A, Padua L, Granata G, Leandri M, Ghignotti I, Plasmati R, Pastorelli F, Heimans JJ, Eurelings M, Meijer RJ, Grisold W, Lindeck Pozza E, Mazzeo A, Toscano A, Russo M, Tomasello C, Altavilla G, Penas Prado M, Dominguez Gonzalez C, Dorsey SG. Rasch-built Overall Disability Scale for patients with chemotherapy-induced peripheral neuropathy (CIPN-R-ODS). Eur J Cancer. 2013;49(13):2910-8.

86. Lavoie Smith EM, Barton DL, Qin R, Steen PD, Aaronson NK, Loprinzi CL. Assessing patient-reported peripheral neuropathy: the reliability and validity of the European Organization for Research and Treatment of Cancer QLQCIPN20 Questionnaire. Qual Life Res. 2013;22:2787-99.

87. Donald GK, Tobin I, Stringer J. Evaluation of acupuncture in the management of chemotherapy-induced peripheral neuropathy. Acupunct Med. 2011;29(3):230-3.

88. Takemoto S, Ushijima K, Honda K, Wada $\mathrm{H}$, Terada A, Imaishi H, Kamura T. Precise evaluation of chemotherapy-induced peripheral neuropathy using the visual analogue scale: a quantitative and comparative analysis of neuropathy occurring with paclitaxel-carboplatin and docetaxel-carboplatin therapy. Int J Clin Oncol. 2012;17(4):367-72.

89. Liu YC, Wang WS. Human mu-opioid receptor gene A118G polymorphism predicts the efficacy of tramadol/acetaminophen combination tablets (ultracet) in oxaliplatin-induced painful neuropathy. Cancer. 2012;118(6):1718-25.

90. Cunningham JE, Kelechi T, Sterba K, Barthelemy N, Falkowski P, Chin SH. Case report of a patient with chemotherapy-induced peripheral neuropathy 
treated with manual therapy (massage). Support Care Cancer. 2011;19(9):1473-6.

91. Durand JP, Deplanque G, Montheil V, Gornet JM, Scotte F, Mir O, Cessot A, Coriat R, Raymond E, Mitry E, Herait P, Yataghene Y, Goldwasser F. Efficacy of venlafaxine for the prevention and relief of oxaliplatin-induced acute neurotoxicity: results of EFFOX, a randomized, double-blind, placebo-controlled phase III trial. Ann Oncol. 2012;23:200-5.

92. Lavoie Smith EM, Cohen JA, Pett MA, Beck SL. The validity of neuropathy and neuropathic pain measures in patients with cancer receiving taxanes and platinums. Oncol Nurs Forum. 2011;38(2):133-42.

93. Smith EM, Cohen JA, Pett MA, Beck SL. The reliability and validity of a modified total neuropathy score-reduced and neuropathic pain severity items when used to measure chemotherapy-induced peripheral neuropathy in patients receiving taxanes and platinums. Cancer Nurs. 2010;33(3):173-83.

94. Burkey AR, Kanetsky PA. Development of a novel location-based assessment of sensory symptoms in cancer patients: preliminary reliability and validity assessment. J Pain Symptom Manag. 2009;37(5):848-62.

95. Bezjak A, Lee CW, Ding K, Brundage M, Winton T, Graham B, Whitehead M, Johnson DH, Livingston RB, Seymour L, Shepherd FA. Quality-of-life outcomes for adjuvant chemotherapy in early-stage non-small-cell lung cancer: results from a randomized trial, JBR.10. J Clin Oncol. 2008;26(31):5052-9.

96. Wong R, Sagar S. Acupuncture treatment for chemotherapy-induced peripheral neuropathy-a case series. Acupunct Med. 2006;24(2):87-91.

97. Durand JP, Alexandre J, Guillevin L, Goldwasser F. Clinical activity of venlafaxine and topiramate against oxaliplatin-induced disabling permanent neuropathy. Anticancer Drugs. 2005;16(5):587-91.

98. Hammack JE, Michalak JC, Loprinzi CL, Sloan JA, Novotny PJ, Soori GS, Tirona MT, Rowland KM Jr, Stella PJ, Johnson JA. Phase III evaluation of nortriptyline for alleviation of symptoms of cis-platinum-induced peripheral neuropathy. Pain. 2002;98(1-2):195-203.

99. Wilson RH, Lehky T, Thomas RR, Quinn MG, Floeter MK, Grem JL. Acute oxaliplatin-induced peripheral nerve hyperexcitability. J Clin Oncol. 2002;20(7):1767-74.

100. Durand JP, Brezault C, Goldwasser F. Protection against oxaliplatin acute neurosensory toxicity by venlafaxine. Anticancer Drugs. 2003;14(6):423-5.
101. Smith EM, Pang H, Cirrincione C, Fleishman S, Paskett ED, Ahles T, Bressler LR, Fadul CE, Knox C, Le-Lindqwister N, Gilman PB, Shapiro CL, Alliance for Clinical Trials in Oncology. Effect of duloxetine on pain, function, and quality of life among patients with chemotherapy-induced painful peripheral neuropathy: a randomized clinical trial. JAMA. 2013;309(13):1359-67.

102. Rao RD, Michalak JC, Sloan JA, Loprinzi CL, Soori GS, Nikcevich DA, Warner DO, Novotny P, Kutteh LA, Wong GY. Efficacy of gabapentin in the management of chemotherapy-induced peripheral neuropathy: a phase 3 randomized, double-blind, placebo-controlled, crossover trial (NO0C3). Cancer. 2007;110(9):2110-8.

103. Tsavaris N, Kopterides P, Kosmas C, Efthymiou A, Skopelitis H, Dimitrakopoulos A, Pagouni E, Pikazis D, Zis PV, Koufos C. Gabapentin monotherapy for the treatment of chemotherapy-induced neuropathic pain: a pilot study. Pain Med. 2008;9(8):1209-16.

104. Filipczak-Bryniarska I, Krzyzewski RM, Kucharz J, Michalowska-Kaczmarczyk A, Kleja J, Woron J, Strzepek K, Kazior L, Wordliczek J, Grodzicki T, Krzemieniecki K. High-dose 8\% capsaicin patch in treatment of chemotherapy-induced peripheral neuropathy: single-center experience. Med Oncol. 2017;34(9):162.

105. Zis P, Rao DG, Sarrigiannis PG, Aeschlimann P, Aeschlimann DP, Sanders D, Grünewald RA, Hadjivassiliou M. Transglutaminase 6 antibodies in gluten neuropathy. Dig Liver Dis. 2017;49(11):1196-200.

106. Thawani SP, Brannagan TH 3rd, Lebwohl B, Green $\mathrm{PH}$, Ludvigsson JF. Risk of neuropathy among 28,232 patients with biopsy-verified celiac disease. JAMA Neurol. 2015;72(7):806-11.

107. Pachman DR, Watson JC, Loprinzi CL. Therapeutic strategies for cancer treatment related peripheral neuropathies. Curr Treat Options Oncol. 2014;15(4):567-80.

108. Rutkove SB, Kothari MJ, Raynor EM, Levy ML, Fadic R, Nardin RA. Sural/radial amplitude ratio in the diagnosis of mild axonal polyneuropathy. Muscle Nerve. 1997;20(10):1236-41.

109. Buschbacher RM. Tibial nerve motor conduction to the abductor hallucis. Am J Phys Med Rehabil. 1999;78(6 Suppl):S15-20.

110. Zis P, Grünewald RA, Chaudhuri RK, Hadjivassiliou M. Peripheral neuropathy in idiopathic Parkinson's disease: a systematic review. J Neurol Sci. 2017;15(378):204-9. 
111. Camdessanché JP, Jousserand G, Ferraud K, Vial C, Petiot P, Honnorat J, Antoine JC. The pattern and diagnostic criteria of sensory neuronopathy: a case-control study. Brain. 2009;132(Pt 7):1723-33.
112. Zis P, Hadjivassiliou M, Sarrigiannis PG, Barker ASTJE, Rao DG. Rapid neurophysiological screening for sensory ganglionopathy: a novel approach. Brain Behav. 2017. https://doi.org/10.1002/brb3. 880 